IZA DP No. 9965

Public Wages, Public Employment, and Business Cycle Volatility: Evidence from U.S. Metro Areas

Claire A. Boeing-Reicher

Vincenzo Caponi

June 2016 


\title{
Public Wages, Public Employment, and Business Cycle Volatility: Evidence from U.S. Metro Areas
}

\author{
Claire A. Boeing-Reicher \\ Kiel Institute for the World Economy (IfW) \\ Vincenzo Caponi \\ CREST - Ensai, \\ IZA, IfW and Ryerson University
}

Discussion Paper No. 9965

May 2016

IZA

P.O. Box 7240

53072 Bonn

Germany

Phone: +49-228-3894-0

Fax: +49-228-3894-180

E-mail: iza@iza.org

Any opinions expressed here are those of the author(s) and not those of IZA. Research published in this series may include views on policy, but the institute itself takes no institutional policy positions. The IZA research network is committed to the IZA Guiding Principles of Research Integrity.

The Institute for the Study of Labor (IZA) in Bonn is a local and virtual international research center and a place of communication between science, politics and business. IZA is an independent nonprofit organization supported by Deutsche Post Foundation. The center is associated with the University of Bonn and offers a stimulating research environment through its international network, workshops and conferences, data service, project support, research visits and doctoral program. IZA engages in (i) original and internationally competitive research in all fields of labor economics, (ii) development of policy concepts, and (iii) dissemination of research results and concepts to the interested public.

IZA Discussion Papers often represent preliminary work and are circulated to encourage discussion. Citation of such a paper should account for its provisional character. A revised version may be available directly from the author. 


\section{ABSTRACT}

\section{Public Wages, Public Employment, and Business Cycle Volatility: Evidence from U.S. Metro Areas*}

Based on data from a cross section of U.S. metro areas, we show that public employment correlates negatively with business cycle volatility, hinting at a stabilizing effect of public employment, while public wages correlate weakly and positively with business cycle volatility, hinting at a destabilizing effect of public wages. To explain these relationships, we set up a search and matching model that contains a government sector and a role for government spending in product markets. This latter mechanism affects how the outside option behaves, and this mechanism can help a search and matching model to generate wage-reducing and stabilizing effects of public employment. Without this mechanism, a search and matching model cannot generate these effects.

\section{JEL Classification: E32, E63, J21}

Keywords: public employment, public wages, business cycle volatility, crowding out, search and matching

Corresponding author:

Vincenzo Caponi

Ensai - Campus de Ker Lann

rue Blaise Pascal - BP 37203

35172 Bruz cedex

France

E-mail: vincenzo.caponi@ensai.fr

\footnotetext{
* We wish to thank seminar participants in Kiel and Rennes. We also wish to thank Antonio Afónso, Pedro Gomes, and the participants at the UECE Conference on Economic and Financial Adjustments. All opinions are those of the authors and not those of their respective institutions. Also, this work has been financed in part by Thyssen Foundation grant Az.10.15.1.015IB.
} 


\section{Introduction}

Based on data for the U.S. at a MSA/NECTA level, we find some puzzling facts about the joint relationships among public wages, the size of public employment, and business cycle volatility. ${ }^{1}$ These facts are puzzling insofar as they are at odds with the implications of current search and matching models. In particular, we find that the relationship between the size of public employment and the volatility of private employment in the U.S. is negative, that is, higher public employment is related to more stable private employment over the business cycle (Figure 1). We also find that the relationship between public wages (or the public wage premium) and private employment volatility is weak but positive (Figure 2). The first fact can be explained by new Keynesian models in which a role for government in product markets, nominal and real rigidities, and rule-of-thumb consumers lead to a stabilizing role for government consumption (which consists mainly of the public wage bill). However, this class of models also predicts a stabilizing role for high public wages, since the public wage bill constitutes a relatively acyclical portion of disposable income. Meanwhile, search and matching models of private employment augmented with public employment can explain our second finding. In this class of models, public employment acts as a competitor to the private sector, so that higher wages paid by the public sector act like an increase in the outside option, crowding out employment in the private sector. However, this class of models does not explain our first finding, since increased employment by the public sector should also act like an increase in the outside option, crowding out employment in the private sector by nearly one-to-one.

In order to solve this puzzle, we first estimate a set of stylized facts using data on U.S. metropolitan areas during the 2000s. A few facts emerge: the level of public employment is associated ambiguously with the level of private employment, but negatively with its volatility and also negatively with private wages. On the other hand, higher public wages are associated negatively with the level of private employment, but positively with its volatility, and also positively with private wages. To explain these facts, we set up a standard search and matching model with separate public and private sectors in general equilibrium, where public employment policies affect product markets and the outside option. We find that our model can explain these facts through three main channels: (1) a bargaining channel, through which the possibility of being employed in the public sector affects the wage bargain in the private sector; (2) a tightness channel, which ties the marginal cost of hiring a worker

\footnotetext{
${ }^{1}$ These data are produced by the BEA's Regional Economic Accounts program, augmented by data from the BLS on the unemployment rate, at a MSA/NECTA level.
} 
with private wages in equilibrium; and (3) an outside option channel, through which income effects propagate the effects of fiscal policy following Baxter and King (1993). Our model does not feature any other rigidities.

Under the bargaining channel, an increase in public employment or public wages makes it marginally more attractive (or less unattractive) to become unemployed, since unemployed people stand the chance to obtain an attractive government job. Through this channel, an increase in public employment puts upward pressure on private wages and downward pressure on private employment. This channel can explain the standard theoretical result that higher public wages are associated with more business cycle volatility; this is because an increase in public wages mimics an increase in the outside option. Secondly, under the tightness channel, private wages vary procyclically, this in turn allows for public wages to affect private wages in equilibrium. Finally, under the outside option channel, which operates through product markets, anything that causes private output and private consumption to fall will also make workers wish to work harder (via an income effect), which in turn drives down the outside option in equilibrium. This fall in the outside option drives down private wages. We argue that this channel can help explain the wage-reducing and stabilizing effects of public employment.

Based on these channels, we show how standard models have a difficulty in matching the wage-reducing and stabilizing effects of public employment; we argue that one way to improve this match is to focus more on general equilibrium effects (the outside option channel) operating through product markets. This is in conjunction with the main focus of the literature, which has been on the bargaining channel. For instance, Quadrini and Trigari (2007) set up a partial equilibrium search and matching model similar to ours, but with directed search. $^{2}$ They go on to solve the model stochastically, finding that high public wages or public employment should drive up volatility in private employment and in total employment. These results are similar to those that arise from our bargaining channel in the absence of the outside option channel. Taking a different approach, Burdett (2012) sets up a model similar to that of Burdett and Mortensen (1998) but with a public sector. Burdett's model predicts that public employment and public wages should crowd out private employment, also through a type of bargaining channel. More recently, Afonso and Gomes (2014) find similar results to ours with respect to the effects of public wages, based on U.S. time series

\footnotetext{
${ }^{2}$ Our baseline model features random search. However, we also examine a variant of our model with directed search; most of our results and intuition, particularly on the importance of a variable outside option, are robust to this variation, although the directed search model has trouble at generating a positive effect of public wages on private wages.
} 
data. They go on to set up a similar model to that of Quadrini and Trigari (2007), which they then solve stochastically. They find that high public wages should crowd out private employment while raising private wages, while high public employment should crowd out private employment (more than one-to-one) while also raising private wages. These effects occur through a combination of the bargaining and tightness channels in the absence of the outside option channel.

Building on this intuition, Gomes (2015) goes on to examine the possibility of using procyclical public wages to stabilize business cycles. ${ }^{3}$ We show that Gomes's results are consistent with some of our findings on the stabilizing role of procyclical public wages. In particular, we find that the response of public wages to private wages is positive in the data, and this procyclicality can help explaining the stabilizing role of public employment on total employment and unemployment. However, we find that public employment has a stabilizing effect on private employment, and not only on total employment and unemployment. Moreover, the fact that public employment is associated with lower private wages points toward another channel for the propagation of fiscal policy beyond the bargaining and tightness channels found in standard search and matching models. Seen in the light of the search and matching literature, our main theoretical contribution is to help search and matching models match the effects of public employment on private employment and public wages.

Our results also help to partially reconcile the search and matching literature with the business cycle stabilization literature. For instance, Galí (1994), Fatás and Mihov (2001), Andrés, Doménech, and Fatás (2008), Reicher (2014), and others find that government spending (and especially government consumption, of which the government wage bill is the largest part) is negatively correlated with volatility in both private output and overall output. However, in a theoretical context, it is difficult but possible to generate a stabilizing effect of government consumption on private output. For instance, Andrés, Doménech, and Fatás (2008) point out that a medium-scale DSGE model with sticky prices and capital adjustment costs still has trouble in replicating the stabilizing effects of government spending on private output, although this problem is alleviated somewhat when rule-of-thumb consumers are inserted into that model, and that model features a high degree of nominal and real rigidities. In light of this literature, our results suggest that a search and matching approach, when

\footnotetext{
${ }^{3}$ In related work, Bradley, Postel-Vinay, and Turon (2015) set up a model with worker-level heterogeneity, which they estimate using British data. They go on to analyze a number of consolidation scenarios, also finding a crowding-out result. Meanwhile, Albrecht, Robayo-Abril, and Vroman (2015) use a similar model to discuss the cross-sectional behavior of wages in Colombian data. In further related work, Caponi (2014) analyzes public wage and employment policies in Italy, finding that differences in public wage and employment policies can account for a large portion of the north-south unemployment differential.
} 
embedded into general equilibrium, can help to alleviate some of these problems without having to add extra rigidities. In addition, our results indicate that it is more generally important to distinguish between public wages and public employment, since these two aspects of fiscal policy can have different theoretical and empirical effects.

\section{Stylized facts on public employment and public wages}

\subsection{Data sources and definitions}

In order to establish our set of empirical stylized facts, we use data produced by the BEA's Regional Economic Accounts program, augmented by data from the BLS on the unemployment rate. The data are annual and cover the period from 2001-2013 (on a NAICS basis), at a MSA/NECTA level. Based on these data, we derive the following series. First of all, private employment is calculated as total employment minus employment in government and government enterprises. Next, the private employment rate is calculated by dividing private employment by population. Next, private productivity is calculated by dividing GDP generated by private industries by private employment. Next, the private wage rate is calculated as earnings generated by private industries divided by private employment. Similarly, the public wage rate is calculated as earnings generated by government and government enterprises divided by employment in government and government enterprises. Next, employment shares in the farm, manufacturing, and construction sectors are calculated as the ratios of total farm, manufacturing, and construction employment, respectively, to private employment. Finally, population data are taken as is. Given these data series, all averages and growth rates are calculated using the formulae $a\left(X_{t}\right)=\left(.5 X_{t}+.5 X_{t-1}\right)$ and $g\left(X_{t}\right)=\left(X_{t}-X_{t-1}\right) / a\left(X_{t}\right)$, respectively, and then MSA-specific averages and standard deviations are calculated using these averages and growth rates.

Our analysis takes a cross-sectional approach, covering four dependent variables at the MSA

level: the log standard deviation of growth in the private employment rate (as a measure of business cycle volatility), the log private wage rate, the private employment rate, and the unemployment rate. For each of these dependent variables, we are interested in the effects of a set of independent variables: the log public wage rate, the public employment rate, log private productivity, the farm, manufacturing, and construction employment shares, and population. We include employment shares and population because these variables are 
known to be related to volatility. For all of these variables, summary statistics are presented in Table 1, over the sample of MSAs with a complete time series of valid records.

For those MSAs with valid records, Figure 1 plots the unconditional relationship between the public employment rate (X axis) and log volatility (Y axis). Figure 1 also plots a best fit OLS regression line. Based on Figure 1, it is possible to say that public employment appears to be negatively related with volatility, and this negative correlation is statistically distinguishable from zero. This correlation is in line with results from the literature on automatic stabilizers, which finds that a larger government is associated with less macroeconomic volatility. Next, Figure 2 plots the unconditional relationship between the log public wage premium over private wages (X axis) and log volatility (Y axis). Figure 2 also plots a best fit OLS regression line. Based on Figure 2, it is possible to say that the public wage premium appears if anything to be positively correlated with volatility, but this positive correlation is not statistically distinguishable from zero. However, we show later that this correlation does become statistically distinguishable from zero when conditioning on productivity, industry shares, etc. What both of these figures show, however, is that this association seems to go in opposite directions when looking at public wages separately from public employment.

\subsection{The endogeneity of public wages and public employment}

While unconditional correlations suggest, if anything, a destabilizing role for public wages and a stabilizing role for public employment, these correlations do not account for two sets of issues: the endogeneity of public wages and employment, and the presence of other factors that may drive wages or employment. To look at these issues, we specify a model of public wages and employment; this model then allows us to disentangle endogenous movements in these objects from exogenous movements that are likely the result of policy.

To see how public wages and public employment vary in response to their private counterparts, we follow Quadrini and Trigari (2007), by positing that public wages or employment are set according to the expressions:

$$
\ln W_{g}=\gamma_{W} \ln W_{p}+b_{w}^{\prime} x_{t}+\ln W_{g}^{*}
$$

and:

$$
E_{g}=\gamma_{E} E_{p}+b_{e}^{\prime} x_{t}+E_{g}^{*}
$$


where $W_{g}$ and $E_{g}$ denote public wages and public employment, $W_{g}^{*}$ and $E_{g}^{*}$ denote an exogenously-determined public wage shifter or public employment shifter, $\gamma_{W}$ and $\gamma_{E}$ give the degree to which private wages or employment feed back into public wages or employment in the cross section, $x_{t}$ denotes a set of control variables (a constant, sectoral employment shares, and population), and $b_{w}$ and $b_{e}$ denote coefficient matrices.

Based on these specifications, the first set of estimates in Table 2 contains estimates of $\gamma_{W}$ and $\gamma_{E}$ derived under the assumptions that cross-sectional variation in productivity is unrelated to cross-sectional variation in $W_{g}^{*}$ or $E_{g}^{*}$ (i.e. that private productivity only affects public wages and public employment through their effects on private wages), that public wages do not respond to private employment, and that public employment does not respond to private wages. These assumptions allow the use of log private productivity as an instrument for either log private wages or log private employment, in separate regressions. Based on these regressions, two-stage least squares estimates of $\gamma_{W}$ and $\gamma_{E}$ indicate that there appears to be some endogenous response of public wages to private wages in the cross section, on the order of 0.22 . However, there does not appear to be a strong response of public employment to private employment. This latter finding provides support for the common assumption, in business cycle studies, of acyclicality in real government consumption or in public employment.

In addition, it is possible that public wages and employment could not only vary in the cross section, but also in a time-series sense. In order to address this possibility, Table 2 also presents a set of time-series estimates of $\gamma_{W}$ and $\gamma_{E}$ based on data from two-year intervals over the period 1969-2013, using real wage data deflated by the national CPI. These estimates are derived under the assumption that shocks to local real public wages and public employment are unrelated to aggregate real private wages and aggregate private employment. In doing this, we follow a set of assumptions similar to those made by Steinsson and Nakamura (2014) when they estimate local military spending multipliers, though we had less luck in estimating local cyclical sensitivities to a precise degree. When use this instrumentation strategy, we arrive at a response of real public wages to real private wages on the order of 0.36 , which is slightly larger than the cross-sectional response. Furthermore, we arrive at a response of public employment to private employment on the order of 0.012 , which suggests that public employment is acyclical or even slightly procyclical. Altogether, however, we find that our time-series estimates present the same basic picture as our cross-sectional estimates: slight procyclicality in public wages, with much less cyclicality in public employment. 


\subsection{The likely effects of public wages and public employment}

To the extent that our identifying assumptions are valid, then the cross-sectional results presented in Table 2 make it possible to estimate the effects of the purged public wage and employment shifters $W_{g}^{*}$ and $E_{g}^{*}$ on volatility, private wages, private employment, and unemployment. Such a set of regression results is presented in Table 3, while a set of results based on un-purged data is presented in Table 4 as a robustness check. Both sets of results confirm the impressions given by Figures 1 and 2, in that they show that higher public employment seems to be associated with less business cycle volatility, while higher public wages are associated with more business cycle volatility. Also, interestingly, a larger manufacturing or construction share of private employment appears to be associated with a more volatility, while there is no clear association between population and volatility. Taken together, these results point toward a positive statistical effect of public wages on the volatility of private employment.

These results also show that higher public wages seem to be associated with higher private wages, as shown by Afonso and Gomes (2014) using aggregate U.S. time series data, while higher public wages are associated with lower private employment and higher total rate of unemployment. Meanwhile, higher public employment seems to be associated with lower private wages, an ambiguous effect on private employment, and a lower total rate of unemployment. The result on private employment seems sensitive to whether or not the data are purged, although both sets of results suggest far from perfect one-to-one crowding out. Altogether, these results suggest that a larger public sector is not uniformly expansionary-public wages and public employment have differing effects on log volatility, private wages, private employment, and total unemployment.

\section{A theoretical model}

Motivated by these stylized facts, we construct a search and matching model in general equilibrium. This model allows for us to solve for the effects of public wages and employment on private wages and employment. When we look at our model in partial equilibrium, our model cannot generate a wage-reducing or stabilizing effect of public employment. However, when we add product markets, our model turns out to fit all of these facts, and it does so through three standard channels: a bargaining channel (which causes public employment 
policies to affect the outside options for workers), a tightness channel (which allows private wages to vary in response to these outside options), and endogenous movements in the outside option itself, through an income effect (which mirrors mechanisms used in standard RBCstyle models, leading to incomplete crowding out). Importantly, our model does not rely on any short-run Keynesian model elements, such as sticky prices or rule-of-thumb consumers. Instead, our model is built with the basic building blocks found in the search and matching literature, and this model structure allows us to engage in the types of steady-state exercises that can be found in that literature.

\subsection{Value functions and the wage bargain}

Production takes place in a search and matching economy, divided into the private and public sectors. Apart from the inclusion of a public sector, this is a standard textbook search and matching economy. In this economy, economic rents are discounted at a rate $r$; private matches are destroyed at a rate $\lambda_{p}$; public matches are destroyed at a rate $\lambda_{g}$; hires from unemployment into private employment occur at a rate $p_{p}$; hires from unemployment into public employment occur at a rate $p_{g}$; workers in private matches are paid a wage $W_{p}$; workers in public matches are paid a wage $W_{g}$; matches produce output at a rate of productivity $\pi$; and unemployed workers earn an outside option $b$. The value functions for workers in public and private matches are given by the two equations:

$$
r V_{p}=W_{p}-\lambda_{p}\left(V_{p}-V_{u}\right)
$$

and:

$$
r V_{g}=W_{g}-\lambda_{g}\left(V_{g}-V_{u}\right)
$$

where $V_{p}$ denotes the value of being in a private match, and $V_{g}$ denotes the value of being in a public match. Furthermore, workers engage in undirected or random search; in this case, the value of unemployment for a worker is given by:

$$
r V_{u}=b+p_{p}\left(V_{p}-V_{u}\right)+p_{g}\left(V_{g}-V_{u}\right)
$$

while the value of employment for a firm in the private sector is given by:

$$
r V_{j}=\pi-W_{p}-\lambda_{p} V_{j}
$$


Firms can hire workers at a (possibly endogenous) marginal cost $c$; free entry implies that the value of a filled job should equal the cost of filling that job, such that:

$$
V_{j}=c
$$

Since these hiring costs create quasi-rents, employed workers and firms Nash bargain over these rents, in order to determine wages. In this bargaining process, workers have a bargaining weight $\beta$ over the match surplus, while firms have a bargaining weight $1-\beta$. This implies that the surplus is split according to the formula:

$$
\beta V_{j}=(1-\beta)\left(V_{p}-V_{u}\right)
$$

Meanwhile, in contrast with the situation faced by the private sector, productivity in the public sector is not a well-defined concept. Instead, we assume that the public employment shifter $E_{g}^{*}$ and the public wage shifter $W_{g}^{*}$ are set exogenously, according to political considerations.

Based on these value functions and bargaining equation, the equilibrium private wage is given by the wage equation:

$$
W_{p}=\beta \pi+\frac{r+\lambda_{g}}{r+\lambda_{g}+p_{g}}\left[(1-\beta) b+\beta c p_{p}\right]+\frac{(1-\beta) p_{g}}{r+\lambda_{g}+p_{g}} W_{g}
$$

This wage equation functions like a labor supply equation. Furthermore, free entry in vacancy posting implies that labor demand follows the equation:

$$
\pi-W_{p}=\left(r+\lambda_{p}\right) c
$$

Holding $b$ and $c$ constant, the intersection between these two equations pins down $W_{p}$ and, implicitly by way of flow rates, private employment.

\subsection{The matching process and steady-state flows}

To pin down employment and vacancy stocks, we assume that matches and employment outflows must be equal in the steady state. Given a Cobb-Douglas matching function over 
vacancies $V$ and searchers $U$, this implies:

$$
V^{a} U^{1-a}=\lambda_{g} E_{g}+\lambda_{p} E_{p} .
$$

Then, letting $\theta=V / U$ and $U=1-E_{g}-E_{p}$, and substituting these into the previous expression, give:

$$
\theta^{a}\left(1-E_{g}-E_{p}\right)=\lambda_{g} E_{g}+\lambda_{p} E_{p} .
$$

In addition, the average cost of hiring a worker $c$ is given by a coefficient $\bar{c}$ divided by the job finding rate (matches per vacancy), such that:

$$
c=\bar{c} \theta^{1-a} .
$$

Furthermore, steady-state flow rates are given by the equations:

$$
p_{g}=\frac{\lambda_{g} E_{g}}{1-E_{g}-E_{p}},
$$

and

$$
p_{p}=\frac{\lambda_{p} E_{p}}{1-E_{g}-E_{p}},
$$

which in turn implicitly pin down private employment.

\subsection{Fiscal policy and government production}

In this model, the government acts as a producer. We assume that government production is Leontief, such that the government purchases $\psi$ units from the private sector for every unit of gross output it produces, at a rate of productivity $\pi$. This means that the government purchases $\psi \pi E_{g}$ additional units of output, such that when government final consumption is measured in private output units, government consumption is given by:

$$
G=\left[\pi-c \lambda_{p}\right] E_{g}+\psi \pi E_{g} .
$$


Next, the government balances its budget, such that tax revenues equal the wage bill plus intermediate government consumption:

$$
T=W_{g} E_{g}+\psi \pi E_{g}
$$

\subsection{Household behavior and the goods market}

The search and matching block of the model sits within a larger macroeconomic environment, in which households trade on the goods market in order to maximize the present discounted value of utility $H_{t}$, subject to a sequence of budget constraints which apply at the household level. Households pool all of their consumption and income among their members. The household's utility function takes the form:

$$
H_{t}=\widetilde{E_{t}} \int_{0}^{\infty} e^{-\rho i}\left[\frac{C_{t+i}^{1-\sigma}}{1-\sigma}+v\left(G_{t+i}\right)-\bar{b}\left(E_{g, t+i}+E_{p, t+i}\right)\right] d i
$$

where $\widetilde{E}$ denotes the expectation operator; $\rho$ is a discount rate; $C_{t+i}$ denotes consumption with a preference parameter $\sigma ; v\left(G_{t+i}\right)$ is a monotonic, increasing function in real government consumption $G_{t+i}$, such that preferences are separable in government consumption and private consumption; and $E_{g, t+i}$ and $E_{p, t+i}$ denote public and private employment, with a marginal disutility given by $\bar{b}$. The budget constraints take the form:

$$
C_{t+i}+T_{t+i}=W_{g, t+i} E_{g, t+i}+W_{p, t+i} E_{p, t+i}+\Pi_{p, t+i}
$$

for consumption $C_{t+i}$, taxes $T_{t+i}$, public wages and employment $W_{g, t+i}$ and $E_{g, t+i}$, and private wages and employment $W_{p, t+i}$ and $E_{p, t+i}$.

Maximization proceeds in a standard way. First, denoting the Lagrange multiplier on the budget constraint by $\Lambda_{t+i}$, the first-order conditions to the maximization problem imply that, in the steady state:

$$
\Lambda=C^{-\sigma}
$$

Furthermore, denoting the marginal disutility of work in consumption units by $b$, this marginal disutility equals $\bar{b} / \Lambda$. In equilibrium, then, $b$ is given by:

$$
b=\bar{b} C^{\sigma} .
$$


This setup endogenizes the outside option in a way that is compatible with the rest of the dynamic general equilibrium literature. As a special case, setting $\sigma$ to zero gives the "standard" search and matching calibration, which implies a risk-neutral, acyclical flow outside option. Meanwhile, setting $\sigma$ to a larger value (such as one) gives an interpretation of the outside option as leisure in the presence of risk aversion, in line with the business cycle literature.

On the firm side, steady-state profits to private firms are given by:

$$
\Pi_{p}=\left[\pi-W_{p}\right] E_{p}-c\left[E_{p}-\left(1-\lambda_{p}\right) E_{p}\right] .
$$

Substituting this condition and the government's budget constraint into the households' budget constraint, and then solving for steady-state values under the assumption of market clearing, gives private consumption as a function of private and public employment, such that:

$$
C=\left[\pi-c \lambda_{p}\right] E_{p}-\psi \pi E_{g}
$$

Through this mechanism, fluctuations in private and public employment affect private consumption, which then can affect the outside option $b$.

\subsection{Theoretical results: the bargaining and tightness channels}

Even though $W_{g}, E_{g}, \theta, c$, and $b$ are, in principle, endogenous, we first decide to look at the comparative statics of private employment and private wages, holding these objects constant. This exercise is equivalent to a situation where $\gamma_{W}=\gamma_{E}=0 ; a=1$; and $\sigma=0$. Setting $a=1$ corresponds to a decision to model hiring costs as straight-up hiring costs, while setting $\sigma=0$ breaks the link between consumption and the outside option, making the outside option acyclical. This choice of parameter values isolates the effects of public employment and wage policies that arise in equilibrium through their effects on the wage bargain; we refer to this channel as the bargaining channel. Complete derivations of the following results can be found in Appendix A.

First, we investigate the effects of a change in the volume of public employment on the volume of private employment, given by $\frac{d E_{p}}{d E_{g}}$. This derivative can be ambiguous in sign (particularly in pathological cases). However, when $W_{g}=W_{p}$ and $\lambda_{g}=\lambda_{p}$, such that there is no public wage premium or difference in job security between public and private 
employment (a symmetric case), this derivative would be exactly -1, implying that public employment perfectly crowds out private employment. Next, we find that the derivative of $E_{p}$ with respect to $W_{g}$ is negative. This result implies that an increase in public wages reduces private employment. Both of these things happen because because the value of unemployment to an unemployed worker rises in the event that that worker may more easily or more lucratively obtain a new public job. This causes workers to become less reluctant to become unemployed, which pushes up their wage bargain. This is shown in the wage equation (9). This story implies that a higher rate of public employment or a higher public wage acts like a negative labor supply shock or a positive shock to the outside option. As with an increase in the outside option, these shifts should result in more business cycle volatility (proxied by a higher responsiveness of log private employment to log productivity), following the logic of Hagedorn and Manovskii (2008).

In spite of these results, neither public employment nor public wages should have any effect on private wages, holding $c$ constant. This is because of the vacancy posting condition (10), which pins down private wages as a function of private productivity $\pi$, the discount rate $r$, the hiring cost $c$, and the private match destruction rate $\lambda_{p}$. In order for public employment and wage policies to affect private wages, therefore, one of these objects will have to be able to vary endogenously. To allow for this to happen, we let $c$ vary by letting the matching function parameter $a$ vary; this allows us to endogenize private wages. We refer to the resulting channel as the tightness channel. Allowing for a tightness channel does not by itself have an effect on the comparative static results for $E_{g}$ under a symmetric calibration; in particular, public employment still perfectly crowds out private employment; public employment drives volatility upward; and public employment still has no effect on private wages. However, the effects of public wages change. In particular, public wages now crowd out private employment and public wages drive volatility upward, as before, but now public wages drive up private wages.

In short, the model with both the bargaining and tightness channels can match some of the stylized facts, namely, the effects of public wages. However, the model does not generate a negative effect of public employment on private wages or on volatility. We consider this discrepancy to represent a puzzle. However, these effects seem to resemble what happens when the outside option $b$ falls in response to an increase in public employment. This is in fact one of the standard channels within the broader macro literature (e.g. Baxter and King (1993)) through which government spending has real effects. In that channel, government purchases crowd out consumption, which in turn causes the relative value of 
leisure to fall, and for workers to consume less leisure. In order to show how this mechanism (the "outside option channel") can help us to resolve our puzzle, we engage in a set of quantitative simulations using a calibrated model. This also allows us to evaluate different public wage and employment policies.

\section{Calibrating a more complex model}

\subsection{Calibrating the main parameters}

We calibrate our model to match aggregate data at a monthly frequency, where possible. These calibration targets are shown in Table 5. Based on cross-sectional averages from our dataset from 2001 to 2013, we target public employment as a share of total employment of 15.79 percent, and we target an unemployment rate of 6.73 percent. Based on JOLTS data for separations minus quits from 2001 to 2013, we target a rate of private separations $\lambda_{p}$ of 1.84 percent per month, and we target a rate of public separations $\lambda_{g}$ of 0.77 percent per month. We target these numbers because our model omits on-the-job search, which comprise the majority of quits. For other parameters, we use standard values from the literature. For instance, we target a discount rate of four percent per year, or 0.33 percent per month. We also normalize productivity $\pi$ to one, without loss of generality. Finally, we calibrate $\gamma_{W}$ and $\gamma_{E}$ to their time-series elasticities of 0.3644 and 0.0124 , respectively, based on the results from Table 2.

There are also some parameters for which direct evidence is difficult to find; for these parameters, we use the literature as a guide. For instance, we target a Nash bargaining weight $\beta$ of 0.5 , which is in keeping with the rest of the literature. Also, we vary the matching function parameter $a$ between one (which allows us to look only at the bargaining channel) and 0.4 (which allows us to look at the tightness channel). We choose this value of 0.4 to follow Elsby and Michaels (2013) and Petrongolo and Pissarides (2001). We also vary the consumption parameter $\sigma$ between zero (the standard search and matching calibration) and one (a standard calibration from the business cycle literature). We also vary the outside option $b$ (or equivalently the hiring cost $c$ ). In our baseline setup, we target a replacement rate $b / W_{p}$ of 0.8342 , based on a value of $c$ equivalent to 0.14 times quarterly wage per worker. We choose this value to follow Elsby and Michaels (2013), Silva and Toledo (2009), and Hall and Milgrom (2008). This is a larger value than that used by Shimer (2005) but it is within 
the range used within the search and matching literature. Furthermore, this larger value is compatible with the estimates of Chodorow-Reich and Karaboulis (2015), in which the outside option includes leisure and home production. Such an interpretation, as shown by Hagedorn and Manovskii (2008), produces more business cycle volatility, which helps the model to better fit the data. Given this controversy, we also look at larger and smaller replacement rates.

\subsection{Calibrating the public wage premium and government demand parameter $\psi$}

There are two additional parameters to calibrate, and those are the steady state public wage premium and the share of outside government purchases in overall government purchases. The problem is that our baseline dataset suggests that the public wage premium is unrealistically large. In fact, the summary statistics presented in Table 1 suggest that public employees are compensated at a rate about 1.42 times as much that of private employees (geometric mean across regions) or about 1.44 times (arithmetic mean across regions). However, most previous studies of the public wage or compensation premium, such as those of Katz and Krueger (1991), Borjas (2002), and Falk (2012a, 2012b) find a significantly smaller premium once they control for worker characteristics, most notably education. However, the estimates of Falk are only for the federal wage and compensation premiums, while we are more interested in a premium that takes federal, state, and local employment into account. Given this, and given that the average size of the public wage premium is an important target for our model, we estimate how large the overall government wage premium is for a typical person based on data from the CPS. We do this in Appendix B, and we arrive at a gross compensation premium of 1.0337 .

Finally, we calculate the government's demand for the output from the private sector, in private worker-productivity-equivalents. To derive this, we note that, based on aggregate NIPA tables, the share of government consumption and gross investment that does not come from value added, as a share of measured value added, equals 0.587. However, this captures government demand measured in public worker-wage-equivalents. To express this in private worker-productivity-equivalents, we correct this by the observed ratio of the wages of public workers to private workers. This gives a target for the ratio of $\psi$ to the private wage $W_{p}$ of 0.848 , which gives a value of $\psi$ of 0.840 . This represents the government's demand for the output of private workers, valued at those workers' productivity levels. 


\section{Simulations based on the calibrated model}

\subsection{Simulating the effects of public wages and public employment}

For the calibrated model, we numerically calculate the following derivatives: the derivative of private employment with respect to the public employment shifter, the derivative of log private wages with respect to the public employment shifter, the derivative of private employment with respect to the log public wage shifter, the derivative of log private wages with respect to the log public wage shifter, the derivative of log private employment with respect to log productivity, and the derivatives of that derivative with respect to the public employment and log public wage shifters. We report these cross-derivatives normalized by the derivative of log private employment with respect to log productivity, so that these cross-derivatives have an interpretation as the derivative of log volatility. In all cases, we vary starred values $E_{g}^{*}$ and $\ln W_{g}^{*}$ to make our results analogous to the econometric exercise in Table $3 .^{4}$

\subsection{The bargaining, tightness, and outside option channels}

As seen in Table 6, model variants (1) $(\sigma=0 ; a=1),(2)(\sigma=0 ; a=0.4)$, and (3) $(\sigma=1 ; a=0.4)$ correspond fairly closely with the cases discussed under the symmetric calibration. In model variant (1), only the bargaining channel operates; model variant (2) adds the tightness channel; and model variant (3) adds the outside option channel.

In model variant (1), the bargaining channel causes an increase in the public employment shifter to strongly crowd out private employment, though the calibrated parameter values now imply that this crowding out is slightly stronger than one-to-one. Furthermore, an increase in the public wage shifter crowds out private employment, as under the symmetric calibration. Taking this model and turning on the tightness channel, as in model variant (2), now implies less crowding out, while an increase in the public employment shifter slightly increases private wages. This effect was zero under the symmetric calibration. However, the positive effect of the public wage shifter on private wages still holds, as under the symmetric

\footnotetext{
${ }^{4} \mathrm{~A}$ bit of care is in order when linking the theoretical results from our simple model with our regression results. This is because, in our regression results, we take employment as a share of the population, while in our theoretical results, we take employment as a share of the labor force. Because the unemployment and employment data come from different datasets, we advise caution.
} 
calibration. This exercise suggests that the theoretical exercise provides a useful set of predictions that hold in the more complex model, and that the model still has trouble in matching the stylized facts without the outside option channel.

Next, taking this model and turning on the outside option channel, as in model variant (3), now implies that a higher public employment shifter crowds out private employment by somewhat less, while a higher public employment shifter slightly decreases private wages. These effects now all point in the same direction as their corresponding regression results, for those results which are statistically distinguishable from zero. Importantly, for this calibration, an increase in the public employment shifter now decreases private wages, and an increase in public employment also helps to stabilize private employment over the business cycle. This is because of the way that the income effect arising through product markets in turn affects workers' outside options. This effect is strong enough to generate realistic stabilizing effects of public employment, while not significantly changing the effects of public wages. As a result, model variant (3) can generate effects that are compatible with the stylized facts, and this occurs through an interaction among all three channels.

\subsection{The effects of public wage and employment policies}

Given the success of the baseline calibration in matching our stylized facts, we then pose the question: What are the model-implied effects of different stabilization policies, proxied by $\gamma_{E}$ and $\gamma_{W}$, on business cycle volatility? To see the effects of these parameters on business cycle volatility, Table 7 shows the simulated derivatives for the benchmark calibration, along with simulated derivatives for four alternative calibrations. These calibrations all target the same steady states as the benchmark calibration.

The first alternative calibration (1) represents a situation in which public wages and public employment are perfectly acyclical. Under such a situation, the derivative of private employment with respect to log productivity increases substantially. This means that the business cycle becomes significantly more volatile for the private sector in comparison with our benchmark scenario. This implies that even current stabilization policies, though incomplete in their scope, do seem to result in more stable business cycles.

The second alternative calibration (2) represents a situation in which log public wages adjust one-to-one with log private wages. This alternative calibration results in much less 
volatile business cycles than either the benchmark or (1). This implies that Gomes's (2015) suggestion to allow public wages to vary procyclically should result in significant business cycle stabilization. The reason that such a policy would help to stabilize business cycles is that the distortions to the bargaining process that arise through government employment policies are allowed to vary more procyclically, and this variation acts to make the value of unemployment (and hence bargained wages) vary more procyclically.

The third alternative calibration (3) represents a situation in which public employment adjusts proportionately with private employment. This alternative calibration results in less volatile business cycles than the situation (1) in which public employment does not adjust. This prediction of the model results from crowding out-if productivity increases, then private employment rises. But, if in response, public employment rises, then crowding out dampens the rise in private employment. As a result, a responsive public sector could help to stabilize private employment, though for reasons that are not compatible with standard intuition. However, the desirability of such policies would depend on how government output enters into the preferences of households (the shape of $v$ and any possible nonseparabilities), which would require us to add more assumptions to the model.

The fourth alternative calibration (4) represents a situation in which public employment and public wages adjust proportionately with private employment and wages. This is a calibration that is compatible with balanced growth. This calibration delivers predictions that are in line with the predictions of alternative calibrations (2) and (3) relative to (1). Under this calibration, business cycle volatility falls drastically in comparison with (1) or with the benchmark, implying that there could be significant possibilities for procyclical public sector wage and employment policies to stabilize the private economy.

\subsection{Effects of the public wage premium $W_{g} / W_{p}$ and outside option $b$}

Next, we investigate the role of the steady state public wage premium $W_{g} / W_{p}$. While our estimates point toward this premium being relatively small, the role of $W_{g}$ in the analytical results suggests that the size of this wage premium may have some effect. To investigate this problem, Table 8 displays simulated derivatives for different steady state calibrations. In particular model variant (1) features no wage premium, such that $W_{g} / W_{p}=1$, and model variant (2) features a wage premium doubled relative to its baseline value, such that 
$W_{g} / W_{p}=1.067$. These two counterfactuals indicate that the baseline results are not sensitive to the exact level of the wage premium, except with respect to the effect of the public employment shifter on log volatility. This stabilizing effect reverses sign when the wage premium is large, which is exactly the type of situation in which the bargaining channel is strengthened in relation to the outside option channel.

The other major parameter which might be expected to affect our results is the outside option $b$, which in our calibration strategy is closely linked with $c$. This parameter has an important effect on volatility, as shown by Hagedorn and Manovskii (2008) and others, who argue that including leisure in $b$ would imply that the effective replacement rate available to workers far exceeds the replacement rate available from unemployment insurance alone. To examine the effects of this calibration choice, model variants (3) and (4) depict situations in which $c / W_{p}$ is set to either half or twice its calibrated value. While a smaller value for $c$ or a larger value for $b$ does not affect the qualitative results of the model relative to the baseline calibration, a larger value for $c$ or a smaller value for $b$ also undoes some of the stabilizing effects of government employment.

\section{Random vs. directed search}

We discuss one more issue related to specification, and that is the specification of random search versus directed search. We find that if we were to specify our model as a directed search model, then the tightness channel would disappear. This would, in turn, cause all fluctuations in private wages to come solely through the outside option channel, which would cause the effects of public wages on private wages to become negative in equilibrium. However, the rest of our results remain. To examine this set of issues, first we present a re-specified model using directed search, and then we present a set of computational results from our directed search model.

\subsection{The directed search model}

Under directed search, unemployed searchers can choose every period whether or not to search for a private job or a public job. They cannot search for both at the same time. This

creates two separate pools of unemployed searchers: the private unemployed (denoted by 
$U_{p}$ ) and the public unemployed (denoted by $U_{g}$ ), such that $U_{p}+U_{g}=U$. Since in every period, workers may freely choose in which pool to search, the expected gains to searching in either pool must be equal, such that:

$$
\frac{\lambda_{p} E_{p}}{U_{p}}\left(V_{p}-V_{u}\right)=\frac{\lambda_{g} E_{g}}{U_{g}}\left(V_{g}-V_{u}\right),
$$

where the value functions are derived the same way as before. In turn, a series of algebra steps similar to those used to derive the wage equation implies that:

$$
\left[\frac{\lambda_{p} E_{p}}{\lambda_{g} E_{g}} \frac{U_{g}}{1-E_{p}-E_{g}-U_{g}}\left(r+\lambda_{g}+p_{g}\right)+p_{p}\right] \frac{\beta}{1-\beta} c=W_{g}-b .
$$

Furthermore, equation (12) no longer holds; this equation is replaced by:

$$
\theta^{a}\left(1-E_{g}-E_{p}-U_{g}\right)=\lambda_{p} E_{p}
$$

with the associated marginal hiring cost given by:

$$
c=\bar{c}\left(\frac{\lambda_{p} E_{p}}{1-E_{p}-E_{g}-U_{g}}\right)^{\frac{1-a}{a}} .
$$

All other value functions and equilibrium relationships hold, as before.

\subsection{Results from the directed search model}

The results from this model are shown in Table 9, in a format analogous to that of Table 6 . Within Table 9, model variants (1) through (3) correspond with directed-search equivalents of the random-search model variants (1) through (3) from Table 7. Comparing both of these tables, model variant $(1)(\sigma=0 ; a=1)$ gives the same results across both specifications. This result makes sense because the modifications to the model come through modifications to the tightness equation (12), which feeds through into hiring costs. However, when $a=1$, tightness does not affect hiring costs, and so the model has the same equilibrium as under

random search. This equilibrium features a strong degree of crowding out in response to both public employment and public wages.

Interestingly, moving to model variant (2) $(\sigma=0 ; a=0.4)$ does not change this result. In this model variant, our simulations suggest that private employment and private wages 
respond exactly the same way to public employment and public wages as they do in model variant (1). While it is difficult to derive this result in closed form, this suggests that adding directed search to a model will destroy the tightness channel, in turn making it difficult to replicate the positive effect of public wages on private wages.

Since model variant (2) now does not feature a tightness channel, model variant (3) is dominated by the bargaining and outside option channels, particularly the latter. This latter channel implies that anything that reduces private employment will also reduce private wages. Because of this effect, this model variant still cannot explain the positive correlation between public wages and private wages, although it does well at generating a stabilizing effect for public employment. Altogether, these results imply that a directed search model can match some of (but not all of) the main stylized facts, particularly when that model features an interaction between product markets and the outside option.

\section{Conclusion}

By looking at a cross section of U.S. metro areas, we have established a few stylized facts related to the effects of public employment and public wages. Our findings suggest that high public employment is associated with relatively little crowding out in private employment, while high public employment is associated with low private wages and with less business cycle volatility. Meanwhile, high public wages are associated with low private employment, with high private wages, and with high business cycle volatility. We argue that these facts can match the predictions of a standard search and matching model augmented with a public sector, so long as that model also allows for government policies to affect product markets, resulting in an endogenous outside option. An endogenous outside option is necessary to match the behavior of private wages after an increase in public employment, and an endogenous outside option also makes it possible for higher public employment to stabilize the business cycle. However, the main mechanisms underlying the effects of public wages seem to work through the bargaining and tightness channels.

While these results appear to be mostly robust to different empirical and theoretical strategies, our results suggest several avenues for future work. First of all, on the empirical side, there remains much to be done in estimating the government wage or compensation premium at the individual level, particularly for state and local workers, and in linking these estimates with geography in a way that cross-sectional variation in the public wage premium could be 
examined. There is also work to be done in precisely estimating the local sensitivity of public wages and public employment to private wages and private employment, so as not to run into problems with weak instruments. Such exercises could help add to the broader understanding of how public wages and employment behave in the United States. Furthermore, on the theoretical side, additional work could help link our results to the DSGE literature. Such a link would entail setting up (and then simulating) a model that features a rich set of macro rigidities, along with additional sources of shocks. Since these models feature richer product markets than the ones we have investigated, these models are well-suited to explain the broader macroeconomic effects of public wage and employment policies. 


\section{A Appendix: Derivation of theoretical results}

This appendix presents a derivation of all of the analytical results discussed in Section 3.5.

\section{A.1 Solving for equilibrium employment}

In what follows, it is necessary to solve for equilibrium employment. First, combining the wage equation (9) with the vacancy posting equation (10) gives an expression linking the endogenous objects $p_{p}$ and $p_{g}$ together such that:

$$
-(1-\beta) \pi+\frac{r+\lambda_{g}}{r+\lambda_{g}+p_{g}}\left[(1-\beta) b+\beta c p_{p}\right]+\frac{(1-\beta) p_{g}}{r+\lambda_{g}+p_{g}} W_{g}+\left(r+\lambda_{p}\right) c=0
$$

By substituting in the flow rates from equations (14) and (15), it becomes possible to solve

for the equilibrium value of $E_{p}$. The equilibrium value of $E_{p}$ can be obtained, after some algebra, by solving the linear equation:

$$
\alpha_{p} E_{p}=\alpha_{c}+\alpha_{g} E_{g}
$$

the coefficients to which are given by:

$$
\begin{aligned}
\alpha_{p} & =\left(r+\lambda_{g}\right)\left[\beta c \lambda_{p}+(1-\beta) \pi-\left(r+\lambda_{p}\right) c-(1-\beta) b\right] \\
\alpha_{c} & =\left(r+\lambda_{g}\right)\left[(1-\beta) \pi-\left(r+\lambda_{p}\right) c-(1-\beta) b\right] \\
\alpha_{g} & =\lambda_{g}\left[(1-\beta) \pi-\left(r+\lambda_{p}\right) c-(1-\beta) W_{g}\right]-\alpha_{c} .
\end{aligned}
$$

This linear representation makes it relatively straightforward to solve for $E_{p}$. In general, however, this will be part of a system that also includes equations (12), (13), and (21), which also jointly determine $\theta, c$, and $b$. 


\section{A.2 The bargaining channel}

\section{A.2.1 Effects on steady state aggregates}

For this exercise, we assume that $\gamma_{W}=\gamma_{E}=0 ; a=1$; and $\sigma=0$. First, we investigate the effects of a change in the volume of public employment on the volume of private employment, based on equation (A.2). Implicitly differentiating this equation yields the derivative of $E_{p}$ with respect to $E_{g}$ given by:

$$
\frac{d E_{p}}{d E_{g}}=\frac{\alpha_{g}}{\alpha_{p}} .
$$

For the symmetric calibration, we assume that $W_{g}=W_{p}$ and $\lambda_{g}=\lambda_{p}$. If this symmetry were to hold, then substituting the vacancy posting condition (10) into the expression for $\alpha_{g}$ would yield:

$$
\alpha_{g}=-\lambda_{p} \beta\left(\left(r+\lambda_{p}\right) c\right)-\alpha_{c}
$$

which after substituting in the expression for $\alpha_{c}$, would imply:

$$
\alpha_{g}=-\left(r+\lambda_{p}\right)\left[\beta c \lambda_{p}+(1-\beta) \pi-\left(r+\lambda_{p}\right) c-(1-\beta) b\right]
$$

However, based on the expression for $\alpha_{p}$, this implies that $\alpha_{g}=-\alpha_{p}$, which implies $\frac{d E_{p}}{d E_{g}}=-1$. This situation is one in which public employment perfectly crowds out private employment.

Next, we investigate the effects of an increase in public wages on private employment, by implicitly differentiating equation (A.2). Doing this, we find that the derivative of $E_{p}$ with respect to $E_{g}$ is given by:

$$
\frac{d E_{p}}{d W_{g}}=\frac{-E_{g} \lambda_{g}(1-\beta)}{\alpha_{p}}
$$

which, for non-pathological calibrations, is negative.

\section{A.2.2 Effects on business cycle volatility}

Next, we proxy business cycle volatility with the first derivative of log employment with respect to log productivity. This derivative captures the sensitivity of the system to business 
cycle shocks, which, following the literature, we treat as changes to productivity. This derivative is given by:

$$
\frac{d \ln \left(E_{p}\right)}{d \pi}=\frac{\left(r+\lambda_{g}\right)(1-\beta)\left(1-E_{p}\right)-r(1-\beta) E_{g}}{E_{p} \alpha_{p}}
$$

which for non-pathological calibrations, is positive. As a result of all of this, the effect of public employment on business cycle volatility is given by:

$$
\frac{d}{d E_{g}}\left[\frac{d \ln \left(E_{p}\right)}{d \pi}\right]=-\frac{r(1-\beta)}{E_{p} \alpha_{p}}-\left[\frac{\left(r+\lambda_{g}\right)(1-\beta)-r(1-\beta) E_{g}}{E_{p}^{2} \alpha_{p}}\right] \frac{d E_{p}}{d E_{g}}
$$

which in principle is ambiguous. However, as a special case, focusing on a symmetric calibration gives:

$$
\frac{d}{d E_{g}}\left[\frac{d \ln \left(E_{p}\right)}{d \pi}\right]=\frac{\left(r+\lambda_{g}\right)(1-\beta)-r(1-\beta)\left(E_{g}+E_{p}\right)}{E_{p}^{2} \alpha_{p}}>0
$$

which implies that higher public employment should result in higher private sector business cycle volatility.

Next, we look at the effect of public wages on business cycle volatility. This is given by:

$$
\frac{d}{d W_{g}}\left[\frac{d \ln \left(E_{p}\right)}{d \pi}\right]=-\left[\frac{\left(r+\lambda_{g}\right)(1-\beta)-r(1-\beta) E_{g}}{E_{p}^{2} \alpha_{p}}\right] \frac{d E_{p}}{d W_{g}}>0,
$$

since $\frac{d E_{p}}{d W_{g}}<0$ for non-pathological calibrations.

\section{A.3 The tightness channel}

We examine the tightness channel channel by letting the matching function parameter $a$ vary; this in turn allows us to endogenize $c$, which in turn allows us to endogenize private wages. We find similar qualitative results to the previous section, although this requires more work to establish.

First, differentiating the composite labor market equilibrium condition (A.2) with respect to $E_{g}$ implies:

$$
\frac{d E_{p}}{d E_{g}}=\frac{\alpha_{g}}{\alpha_{p}}+\varpi \frac{d c}{d E_{g}}
$$


for some constant $\varpi$. However, since under the symmetric calibration, $\alpha_{g}=-\alpha_{p}$, then the derivative of $E_{p}$ with respect to $E_{g}$ is given by:

$$
\frac{d E_{p}}{d E_{g}}=-1+\varpi \frac{d c}{d E_{g}}
$$

Next, we need to look at $\frac{d c}{d E_{g}}$. To do this, first, we rearrange equation (13) to express $c$ as a function of $E_{p}$ and $E_{g}$, such that:

$$
c=\bar{c}\left(\frac{\lambda_{g} E_{g}+\lambda_{p} E_{p}}{1-E_{p}-E_{g}}\right)^{\frac{1-a}{a}} .
$$

Differentiating this expression with respect to $E_{g}$ implies that:

$$
\frac{d c}{d E_{g}}=\eta\left[1+\frac{d E_{p}}{d E_{g}}\right]
$$

for some coefficient $\eta$. Combining this equation with equation (A.12) implies:

$$
\frac{d E_{p}}{d E_{g}}=-1+\varpi \eta\left[1+\frac{d E_{p}}{d E_{g}}\right]
$$

Solving this expression for $\frac{d E_{p}}{d E_{g}}$ implies that $\frac{d E_{p}}{d E_{g}}=-1$ as before, and that $\frac{d c}{d E_{g}}=0$. Furthermore, differentiating (12) implies that $\frac{d \theta}{d E_{g}}=0$, and differentiating the vacancy posting equation (10) implies that $\frac{d W_{p}}{d E_{g}}=0$.

Next, implicitly differentiating the vacancy posting condition (10) implies that the derivative of $W_{p}$ with respect to $W_{g}$ is given by:

$$
\frac{d W_{p}}{d W_{g}}=-\left(r+\lambda_{p}\right) \frac{d c}{d W_{g}}
$$

To investigate this derivative, it is necessary to look at $\frac{d c}{d W_{g}}$. To do this, differentiating the expression (A.13) with respect to $W_{g}$ implies that:

$$
\frac{d c}{d W_{g}}=\eta \frac{d E_{p}}{d W_{g}}
$$

for the same positive value of $\eta$ from above. Substituting this into the expression (A.16) 
implies:

$$
\frac{d W_{p}}{d W_{g}}=-\left(r+\lambda_{p}\right) \eta \frac{d E_{p}}{d W_{g}} .
$$

Turning to the calculation of this derivative, differentiating equation (A.2) with respect to $W_{g}$, after some algebra, implies:

$$
\alpha_{p} \frac{d E_{p}}{d W_{g}}+\left[E_{p}\left(r+\lambda_{g}\right) \beta c+\left(1-E_{p}\right)\left(r+\lambda_{g}\right)\left(r+\lambda_{p}\right)-E_{g} r\left(r+\lambda_{p}\right)\right] \eta \frac{d E_{p}}{d W_{g}}=\alpha_{g} .
$$

This expression implies that, for non-pathological calibrations, $\frac{d E_{p}}{d W_{g}}<0$, which in turn implies that $\frac{d W_{p}}{d W_{g}}>0$. 


\section{B Appendix: Estimating the government compensation premium}

To estimate the government compensation premium, we follow Falk (2012a) in estimating the following regression using earnings per hour from 2001 to 2013 as reported in the following year's March Current Population Survey (CPS):

$$
\ln W_{i, t}=\gamma_{G, t} \mathbb{1}_{G, i, t}+b_{G}^{\prime} X_{i, t}+\varepsilon_{i, t},
$$

where $W_{i, t}$ is earnings per hour; $\mathbb{1}_{G, i, t, t}$ is an indicator variable equal to one if a worker worked in the government sector in time $t$ and zero otherwise; $\gamma_{G, t}$ is the effect of public employment on log wages in time $t ; X_{i, t}$ is a vector of control variables including time dummies, seven categories for educational attainment (unknown, through grade 6, through grade 11, a high school diploma or equivalent, an associate's degree, a bachelor's degree, or anything beyond a bachelor's degree), five racial categories (unknown, white, black, native American, and anything else), state dummies, coded sex, and a third-degree polynomial in age; $b_{G}$ is a vector of coefficients; and $\varepsilon_{i, t}$ is a white noise error term. In estimating this regression, we restrict our sample to native-born US citizens who lived in one of the fifty states or DC, reported usual hours of work strictly greater than 34 per week, worked strictly more than 51 weeks, were strictly over 15 years in age, were wage and salary workers, and reported wage and salary income for that year. Unfortunately, we are not able to adequately control for occupation (which is endogenous to the choice of sector) or metro area, since these things are badly measured in our dataset, and our sample is too small to adequately control for metro area. This is particularly unfortunate since this hinders a proper cross-sectional comparison between the BEA and the CPS datasets. We also do not control for firm size, since this is also endogenous to the choice of sectors.

In order to arrive at a public wage premium based on these regressions, we then calculate an arithmetic public wage premium for each year $t$ based on the sample analogue to following formula:

$$
W_{t}^{p r}=\frac{\mathbb{E}\left(\exp \left(\gamma_{G, t}+\varepsilon_{i, t}\right) \mid \mathbb{1}_{G, i, t}=1\right)}{\mathbb{E}\left(\exp \left(\varepsilon_{i, t}\right) \mid \mathbb{1}_{G, i, t}=0\right)} .
$$

This estimate of the arithmetic wage premium explicitly includes exponentiated error terms $\varepsilon_{i, t}$ which have a smaller variance for government workers than for private workers, because of the way that wages are bargained. This is important since Jensen's inequality implies that 
this wage compression should push the arithmetic government wage premium down below the geometric wage premium given by $\exp \left(\gamma_{G, t}\right)$.

A time series of geometric and arithmetic means for the estimated object $W_{t}^{p r}$ can be found in Table B1. This table shows that, over the course of our sample, the average government worker earns a wage 0.931 times as large as the that of the average comparable private worker, and that this ratio is somewhat smaller than that estimated using a geometric mean. Furthermore, this table shows that this ratio seems to have trended slightly upward over time, particularly during the Great Recession. This is in line with the idea that public wages only partially adjust in response to movements in private wages, since private wages were sluggish during that time. Furthermore, some additional checks reveal that our low estimates for the public wage ratio are caused by the presence of state and local workers in our sample. In fact, running the wage regression but separately controlling for federal or state and local workers yields an arithmetic mean federal wage premium of 1.150 and an arithmetic mean state and local wage premium of 0.879 (not shown). These results are much more in line with those of Falk (2012a).

However, it is important to point out that this measured wage premium excludes supplements to wages and salaries, particularly health care and pension benefits. This is an important omission, because as Falk (2012b) points out, a larger share of federal compensation than private compensation comes in the form of these supplements. In fact, using data provided in Table 1 of Falk (2012b), total compensation for full time federal workers, excluding paid leave, exceeds wages by a ratio of 1.461 , while a similar ratio for private workers is given by 1.316. When we apply these ratios to the wage premium for the total government, thereby implicitly assuming that the government sector as a whole behaves like the federal sector in this respect, we arrive at a government compensation premium of 1.034 (or 1.0337). This suggests that the average government worker likely does earn a modest premium over a comparable private worker, though the exact size of this premium depends on the systematic ways in which the total government sector might differ from the federal sector with respect to benefits. 


\section{References}

Afonso, António, and Pedro Gomes, 2014. "Interactions between private and public sector wages." Journal of Macroeconomics 39A, pages 97-112.

Albrecht, James, Monica Robayo-Abril, and Susan Vroman, 2015. "Public Sector Employment in an Equilibrium Search and Matching Model." Mimeo.

Andrés, Javier, Rafael Doménech, and Antonio Fatás, 2008. "The Stabilizing Role of Government Size." Journal of Economic Dynamics and Control 32(2), pages 571-593.

Baxter, Marianne, and Robert G. King, 1993. "Fiscal policy in general equilibrium." The American Economic Review 83(3), pages 315-334.

Borjas, George J., 2002. "The wage structure and the sorting of workers into the public sector." NBER Working Paper 9313.

Bradley, Jake, Fabien Postel-Vinay, and Hélène Turon, 2015. "Public Sector Wage Policy and Labor Market Equilibrium: A Structural Model." Mimeo.

Burdett, Ken, 2012. "Towards a theory of the labor market with a public sector." Labour Economics 19(1), pages 68-75.

Burdett, Ken, and Dale Mortensen, 1998. "Wage differentials, employer size and unemployment." International Economic Review 39(2), pages 257-273

Caponi, Vincenzo, 2014. "Public Employment Policies and Regional Unemployment Differences." IZA Discussion Paper 8511.

Chodorow-Reich, Gabriel, and Loukas Karabarbounis, 2015. "The Cyclicality of the Opportunity Cost of Employment." Mimeo.

Elsby, Michael W.L., and Ryan Michaels, 2013. "Marginal Jobs and Heterogeneous Firms." American Economic Journal: Macroeconomics 5(1), pages 1-48.

Falk, Justin, 2012a. "Comparing Wages in the Federal Government and the Private Sector." CBO Working Paper 2012-3, January 2012.

Falk, Justin, 2012b. "Comparing Benefits and Total Compensation in the Federal Government and the Private Sector." CBO Working Paper 2012-4, January 2012.

Fatás, Antonio, and Ilian Mihov, 2001. "Government size and automatic stabilizers: international and intranational evidence." Journal of International Economics 55(1), pages 3-28. 
Galí, Jordi, 1994. "Government size and macroeconomic stability." European Economic Review 38(1), pages 117-132.

Gomes, Pedro, 2015. "Optimal public sector wages." The Economic Journal 125(587), pages 1425-1451.

Hagedorn, Marcus, and Iourii Manovskii, 2008. "The Cyclical Behavior of Equilibrium Unemployment and Vacancies Revisited." The American Economic Review 98(4), pages 1692-1706.

Hall, Robert E., and Paul R. Milgrom, 2008. "The Limited Influence of Unemployment on the Wage Bargain." American Economic Review 98(4), pages 1653-1674.

Katz, Lawrence F., and Alan B. Krueger, 1991. "Changes in the Structure of Wages in the Public and Private Sectors." Research in Labor Economics 12, pages 137-172.

Quadrini, Vincenzo, and Antonella Trigari, 2007. "Public Employment and the Business Cycle." Scandinavian Journal of Economics 109(4), pages 723-742.

Petrongolo, Barbara, and Christopher A. Pissarides, 2001. "Looking into the Black Box: A Survey of the Matching Function." Journal of Economic Literature 39(2), pages 390-431.

Reicher, Claire A., 2014. "A set of estimated fiscal rules for a cross-section of countries: Stabilization and consolidation through which instruments?" Journal of Macroeconomics 42, pages 184-198.

Shimer, Robert, 2005. "The Cyclical Behavior of Equilibrium Unemployment and Vacancies." The American Economic Review 95(1), pages 25-49.

Silva, Jose I., and Manuel Toledo, 2009. "Labor Turnover Costs and the Cyclical Behavior of Vacancies and Unemployment." Macroeconomic Dynamics 13(S1), pages 76-96. 
Table 1: Summary statistics for observables

\begin{tabular}{rrrrr}
\hline & Mean & Std. & Min. & Max. \\
\hline Log private wage $W_{p}$ & 3.66 & 0.16 & 3.26 & 4.39 \\
Private employment rate $E_{p}$ & 0.478 & 0.079 & 0.232 & 0.690 \\
Log private prod. $\pi$ & -2.74 & 0.20 & -3.26 & -2.03 \\
Log public wage $W_{g}$ & 4.02 & 0.14 & 3.72 & 4.53 \\
Public employment rate $E_{g}$ & 0.0896 & 0.0422 & 0.0365 & 0.3508 \\
Unemployment rate $U$ & 0.0672 & 0.0193 & 0.0323 & 0.2108 \\
Farm share & 0.0228 & 0.0220 & 0.0003 & 0.1521 \\
Mfg. share & 0.1059 & 0.0597 & 0.0156 & 0.4194 \\
Constr. share & 0.0712 & 0.0163 & 0.0266 & 0.1309 \\
Population $(\mathrm{m})$ & 0.621 & 1.243 & 0.060 & 12.765 \\
\hline
\end{tabular}

This table features the cross-sectional sample mean, standard deviation, minimum, and maximum for the main observables. Note that to make private productivity comparable to the private or public wage, one should add $\ln (1000)$ to log private productivity. Source: BEA, BLS, and authors' calculations. 
Table 2: Regression results: likely effects of private wages or employment on public wages or employment

\begin{tabular}{rrrrr}
\hline \multicolumn{3}{c}{ Cross-sectional } & \multicolumn{2}{c}{ Time-series } \\
\hline & Log pub. wage & Pub. empl. & Log pub. wage & Pub. empl. \\
\hline Log private wage & 0.222 & & 0.364 & \\
(std.) & 0.062 & & 0.016 & 0.012 \\
Private employment & & -0.087 & & 0.005 \\
(std.) & & 0.078 & & \\
Farm share & 0.208 & -0.169 & & \\
(std.) & 0.343 & 0.132 & & \\
Mfg. share & -0.912 & -0.211 & & \\
(std.) & 0.135 & 0.045 & & \\
Constr. share & -1.499 & -0.415 & & \\
(std.) & 0.515 & 0.181 & & \\
Population (m) & 0.018 & -0.006 & & \\
(std.) & 0.007 & 0.002 & & \\
\hline$N$ & 306 & 306 & & \\
\hline First-stage $F$ & 1,067 & 61.9 & 4,175 & \\
\hline
\end{tabular}

This set of regressions captures the likely effects of private wages and private employment on public wages and employment, using log private productivity as an instrument for either private wages or private employment, in levels for the cross-sectional elasticities. For the time-series elasticities, two-year first differences are taken, with aggregate first-differences taken as instruments. The dependent variables are the $\log$ public wage $W_{g}$ and public employment per capita $E_{g}$. The independent variables are the log private

wage $W_{p}$, the private employment rate $E_{p}$, the shares of farm, manufacturing, and construction employment in private employment, and population (independent variables), at an MSA or NECTA level. The data are cross-sectional averages taking the average of period $t$ and $t-1$ observations, in accordance with the timing assumptions used to derive growth rates. Coefficient estimates are followed by standard errors, and the row of the table lists the number of observations $(N)$. Source: BEA, BLS, and authors' calculations. 
Table 3: Regression results: effects of public wages and employment, purged

\begin{tabular}{rrrrr}
\hline & Log vol. & Log priv. wage & Priv. empl. & Unempl. \\
\hline Log public wage shifter & 0.476 & 0.092 & -0.139 & 0.042 \\
(std.) & 0.130 & 0.032 & 0.031 & 0.009 \\
Public employment shifter & -1.395 & -0.266 & -0.010 & -0.164 \\
(std.) & 0.360 & 0.080 & 0.098 & 0.026 \\
Log private prod. & 0.091 & 0.651 & 0.167 & -0.006 \\
(std.) & 0.099 & 0.029 & 0.019 & 0.005 \\
Farm share & 1.079 & -0.058 & -0.696 & 0.313 \\
(std.) & 0.727 & 0.135 & 0.205 & 0.074 \\
Mfg. share & 1.280 & 0.174 & 0.135 & 0.019 \\
(std.) & 0.430 & 0.064 & 0.076 & 0.021 \\
Constr. share & 6.509 & -1.909 & -1.022 & -0.040 \\
(std.) & 1.259 & 0.351 & 0.305 & 0.087 \\
Population (m) & 0.027 & 0.012 & -0.004 & 0.002 \\
$($ std.) & 0.009 & 0.005 & 0.002 & 0.0004 \\
\hline$R^{2}$ & 0.254 & 0.868 & 0.378 & 0.298 \\
$N$ & 306 & 306 & 306 & 306
\end{tabular}

This set of regressions captures the unconditional cross-sectional statistical relationships among a set of dependent variables and independent variables. The dependent variables are the log standard deviation of

the growth rate of private employment per capita (log volatility), the log private wage $W_{p}$, private employment per capita $E_{p}$, and the unemployment rate $U$. The dependent variables are the log public wage shifter $W_{g}^{*}$, the public employment shifter $E_{g}^{*}$, the log private productivity level, the shares of farm, manufacturing, and construction employment in private employment, and population (independent variables), at an MSA or NECTA level. The data are cross-sectional averages taking the average of period $t$ and $t-1$ observations, in accordance with the timing assumptions used to derive growth rates. Furthermore, the shifters are derived by "purging" log public wages and public employment of the effects of private wages and employment, employment shares, and population, using the coefficients in Table 2. Coefficient estimates are followed by robust standard errors, and the bottom two rows of the table list the R-squared values of each regression and the number of observations $(N)$. Source: BEA, BLS, and authors' calculations. 
Table 4: Regression results: effects of public wages and employment, un-purged

\begin{tabular}{rrrrr}
\hline & Log vol. & Log priv. wage & Priv. empl. & Unempl. \\
\hline Log public wage & 0.418 & 0.147 & -0.112 & 0.039 \\
(std.) & 0.128 & 0.031 & 0.029 & 0.009 \\
Public employment & -1.136 & -0.323 & -0.239 & -0.127 \\
(std.) & 0.349 & 0.085 & 0.081 & 0.023 \\
Log private prod. & 0.012 & 0.626 & 0.181 & -0.013 \\
(std.) & 0.104 & 0.029 & 0.019 & 0.005 \\
Farm share & 0.866 & -0.115 & -0.696 & 0.291 \\
(std.) & 0.745 & 0.135 & 0.208 & 0.075 \\
Mfg. share & 1.390 & 0.233 & -0.015 & 0.025 \\
(std.) & 0.448 & 0.069 & 0.086 & 0.021 \\
Constr. share & 7.038 & -1.803 & -1.360 & 0.001 \\
(std.) & 1.263 & 0.317 & 0.309 & 0.083 \\
Population (m) & 0.012 & 0.007 & -0.003 & 0.0005 \\
(std.) & 0.010 & 0.005 & 0.002 & 0.0005 \\
\hline$R^{2}$ & 0.240 & 0.877 & 0.383 & 0.254 \\
$N$ & 306 & 306 & 306 & 306
\end{tabular}

This set of regressions captures the unconditional cross-sectional statistical relationships among a set of dependent variables and independent variables, which are not purged of the likely effects of private wages and employment. This is a robustness check to the results presented in Table 3. The dependent variables are the $\log$ standard deviation of the growth rate of private employment per capita (log volatility), the log private wage $W_{p}$, private employment per capita $E_{p}$, and the unemployment rate $U$. The dependent variables are the log public wage level $W_{g}$, public employment per capita $E_{g}$, the $\log$ private productivity

level, the shares of farm, manufacturing, and construction employment in private employment, and population (independent variables), at an MSA or NECTA level. Wages and productivity are equal to private compensation and private GDP per employee, respectively. The data are cross-sectional averages taking the average of period $t$ and $t-1$ observations, in accordance with the timing assumptions used to derive growth rates. Coefficient estimates are followed by robust standard errors, and the bottom two rows of the table list the R-squared values of each regression and the number of observations $(N)$. Source: BEA,

BLS, and authors' calculations. 
Table 5: Model calibration, baseline model

\begin{tabular}{rrrl}
\hline Target & Description & Value & Remarks \\
\hline$W_{g} / W_{p}$ & Gross pub. wage premium & 1.0337 & CPS data \\
$E_{g} /\left(E_{g}+E_{p}\right)$ & Public employment share & 0.1579 & Cross-sectional mean \\
$U$ & Unemployment rate & 0.0673 & Cross-sectional mean \\
$\lambda_{p}$ & Private sep. rate & 0.0184 & JOLTS nationwide mean \\
$\lambda_{g}$ & Public sep. rate & 0.0077 & JOLTS nationwide mean \\
$r$ & Discount rate & 0.0033 & Target: 4 percent per year \\
$\beta$ & Workers' bargaining power & 0.5 & Standard calibration \\
$c / W_{p}$ & Hiring cost & 0.42 & Target of 0.14/qtr, monthly \\
$b / W_{p}$ & Replacement rate & 0.8342 & Derived from $c$ \\
$\psi / W_{p}$ & Govt. demand parameter & 0.8476 & NIPA, cross-sectional data \\
$\pi$ & Productivity & 1 & Normalization \\
$a$ & Match elasticity & 0.4 & Petrongolo and Pissarides (2001) \\
$\sigma$ & Consumption utility parameter & 1 & Log preferences \\
$\gamma_{W}$ & Response of pub. to priv. wages & 0.3644 & Time-series elasticity \\
$\gamma_{E}$ & Response of pub. to priv. empl. & 0.0124 & Time-series elasticity \\
\hline
\end{tabular}

This table lists a set of model calibrations for the baseline random search model calibrated to cross-sectional means (or aggregate means) for U.S. data, from 2001 to 2013. Source: BEA, BLS, and authors' calculations. 
Table 6: Implied responses, varying $a$ and $\sigma$, baseline model

\begin{tabular}{rcccc}
\hline Object & $\mathbf{( 1 )}$ & $\mathbf{( 2 )}$ & $\mathbf{( 3 )}$ & Data \\
\hline$a$ & 1.0 & 0.4 & 0.4 & \\
$\sigma$ & 0.0 & 0.0 & 1.0 \\
\hline Responses to log public wage shifter \\
Log volatility & 5.393 & 7.889 & 3.169 & 0.476 \\
Log private wages & 0.000 & 0.062 & 0.052 & 0.092 \\
Private employment & -0.642 & -0.280 & -0.235 & -0.229 \\
\hline Responses to public employment shifter \\
Log volatility & 5.719 & 5.889 & -0.809 & -0.848 \\
Log private wages & 0.000 & 0.017 & -0.060 & -0.162 \\
Private employment & -1.120 & -1.022 & -0.676 & -0.010 \\
\hline Responses to log private productivity \\
Log volatility & -12.002 & -11.575 & -1.871 & 0.091 \\
Log private wages & 1.009 & 0.932 & 0.972 & 0.651 \\
Private employment & 0.796 & 0.347 & 0.168 & 0.275 \\
\hline \multicolumn{5}{c}{}
\end{tabular}

This table lists a set of model calibrations and implied (semi-)elasticities for the baseline random search model calibrated to cross-sectional averages for U.S. data, from 2001 to 2013 . Model variant (1) is the baseline model with just the bargaining channel. Model variant (2) adds the tightness channel onto that model. Model variant (3) adds a variable outside option, following the business cycle literature. The fourth column contains analogous values from the data, based on estimates from Table 3, taking the implied labor force participation rate (0.6073) into account. Values in italics are statistically indistinguishable from zero. 
Table 7: Sensitivity to public policy changes, varying $\gamma_{W}$ and $\gamma_{E}$

\begin{tabular}{rrrrrr}
\hline Object & Benchmark & $\mathbf{( 1 )}$ & $\mathbf{( 2 )}$ & $\mathbf{( 3 )}$ & $\mathbf{( 4 )}$ \\
\hline$\gamma_{W}$ & 0.3644 & 0.0000 & 1.0000 & 0.0000 & 1.0000 \\
$\gamma_{E}$ & 0.0124 & 0.0000 & 0.0000 & 0.1875 & 0.1875 \\
\hline Responses to log public & wage shifter & & & \\
Log volatility & 3.169 & 3.428 & -3.135 & 3.553 & -3.020 \\
Log private wages & 0.052 & 0.051 & 0.054 & 0.053 & 0.056 \\
Private employment & -0.235 & -0.233 & -0.246 & -0.207 & -0.218 \\
\hline Responses to public employment & shifter \\
Log volatility & -0.809 & -0.848 & -0.713 & -1.368 & -1.267 \\
Log private wages & -0.060 & -0.060 & -0.063 & -0.053 & -0.056 \\
Private employment & -0.676 & -0.687 & -0.673 & -0.609 & -0.597 \\
\hline Responses to log private productivity & & & \\
Log volatility & -1.871 & -3.277 & -0.360 & -3.415 & -0.369 \\
Log private wages & 0.972 & 0.954 & 1.005 & 0.951 & 1.005 \\
Private employment & 0.168 & 0.251 & 0.018 & 0.223 & 0.016 \\
\hline
\end{tabular}

This table lists a set of model calibrations and implied (semi-)elasticities for the random search model calibrated to cross-sectional averages for U.S. data, from 2001 to 2013. Model variant (1) is the baseline model with no response of public wages or public employment to their private counterparts. Model variant

(2) adds full adjustment (1:1) in public wages to model (1). Model variant (3) adds full adjustment in public employment to model (1). Model variant (4) adds full adjustment in public wages and public employment to model (1). 
Table 8: Sensitivity to steady states, varying $W_{g} / W_{p}$ and $b / W_{p}$

\begin{tabular}{rrrrrr}
\hline Object & Benchmark & $\mathbf{( 1 )}$ & $\mathbf{( 2 )}$ & $\mathbf{( 3 )}$ & $\mathbf{( 4 )}$ \\
\hline$W_{g} / W_{p}$ & 1.0337 & 1.0000 & 1.0674 & 1.0337 & 1.0337 \\
$c / W_{p}$ & 0.4200 & 0.4200 & 0.4200 & 0.2100 & 0.8400 \\
$b / W_{p}$ & 0.8353 & 0.8867 & 0.7838 & 0.8919 & 0.7220 \\
\hline Responses to log public & wage shifter & & & \\
Log volatility & 3.169 & 3.566 & 2.873 & 2.101 & 2.715 \\
Log private wages & 0.052 & 0.056 & 0.049 & 0.039 & 0.062 \\
Private employment & -0.235 & -0.255 & -0.220 & -0.355 & -0.140 \\
\hline Responses to public employment & shifter & & \\
Log volatility & -0.809 & -3.286 & 1.051 & -2.299 & 1.810 \\
Log private wages & -0.060 & -0.087 & -0.039 & -0.050 & -0.058 \\
Private employment & -0.676 & -0.560 & -0.771 & -0.500 & -0.817 \\
\hline Responses to log private productivity & & & \\
Log volatility & -1.871 & -2.116 & -1.691 & -1.143 & -1.695 \\
Log private wages & 0.972 & 0.969 & 0.974 & 0.978 & 0.969 \\
Private employment & 0.168 & 0.182 & 0.156 & 0.239 & 0.111 \\
\hline
\end{tabular}

This table lists a set of model calibrations and implied (semi-)elasticities for the random search model calibrated to cross-sectional averages for U.S. data, from 2001 to 2013 . Model variant (1) is the baseline model with no public wage premium. Model variant (2) is the baseline model but with double the wage premium. Model variant (3) is the baseline model with the ratio $c / W_{p}$ set to half its baseline value. Model variant (4) is the baseline model with the ratio $c / W_{p}$ set to double its baseline value. 
Table 9: Implied responses, varying $a$ and $\sigma$, directed search model

\begin{tabular}{ccccc}
\hline Object & $\mathbf{( 1 )}$ & $\mathbf{( 2 )}$ & $\mathbf{( 3 )}$ & Data \\
\hline$a$ & 1.0 & 0.4 & 0.4 & \\
$\sigma$ & 0.0 & 0.0 & 1.0 & \\
\hline Responses to log public wage & shifter \\
Log volatility & 5.393 & 6.636 & -4.573 & 0.476 \\
Log private wages & 0.000 & 0.000 & -0.021 & 0.092 \\
Private employment & -0.642 & -0.642 & -0.501 & -0.229 \\
\hline Responses to public employment shifter \\
Log volatility & 5.719 & 6.944 & -0.575 & -0.848 \\
Log private wages & 0.000 & 0.000 & -0.065 & -0.162 \\
Private employment & -1.120 & -1.120 & -0.695 & -0.010 \\
\hline Responses to log private productivity \\
Log volatility & -12.002 & -10.542 & 3.028 & 0.091 \\
Log private wages & 1.009 & 0.976 & 1.018 & 0.651 \\
Private employment & 0.796 & 0.604 & 0.335 & 0.275 \\
\hline
\end{tabular}

This table lists a set of model calibrations and implied (semi-)elasticities for the baseline directed search model calibrated to cross-sectional averages for U.S. data, from 2001 to 2013 . Model variant (1) is the directed search model with just the bargaining channel. Model variant (2) adds the tightness channel onto that model. Model variant (3) adds a variable outside option, following the business cycle literature. The fourth column contains analogous values from the data, based on estimates from Table 3, taking the implied labor force participation rate (0.6073) into account. Values in italics are statistically indistinguishable from zero. 
Table B1: Gross public wage premium based on CPS data

\begin{tabular}{rrrr}
\hline Year & Gross wage prem. & Gross wage prem. & Gross comp. prem. \\
\hline 2001 & (Geometric) & (Arithmetic) & (Arithmetic) \\
2002 & 0.925 & 0.873 & \\
2003 & 0.951 & 0.902 & \\
2004 & 0.957 & 0.933 & \\
2005 & 0.978 & 0.933 & \\
2006 & 0.976 & 0.926 & \\
2007 & 0.986 & 0.953 & \\
2008 & 0.968 & 0.926 & \\
2009 & 0.968 & 0.921 & \\
2010 & 0.984 & 0.941 & \\
2011 & 0.989 & 0.954 & \\
2012 & 0.901 & 0.937 & \\
2013 & 0.997 & 0.956 & \\
\hline Mean & 0.946 & 0.909 & \\
\hline
\end{tabular}

This time series displays the estimated gross public wage premium $W_{t}^{p r}$ for the years 2001 through 2013, based on CPS data and the authors' calculations. The time-series mean is calculated according to the timing conventions used elsewhere in the paper. The compensation premium is equal to mean wages adjusted using the ratios of federal and private compensation to wages for workers who worked full time, provided by Falk (2012b). 
Figure 1: Log public employment rate vs. log volatility

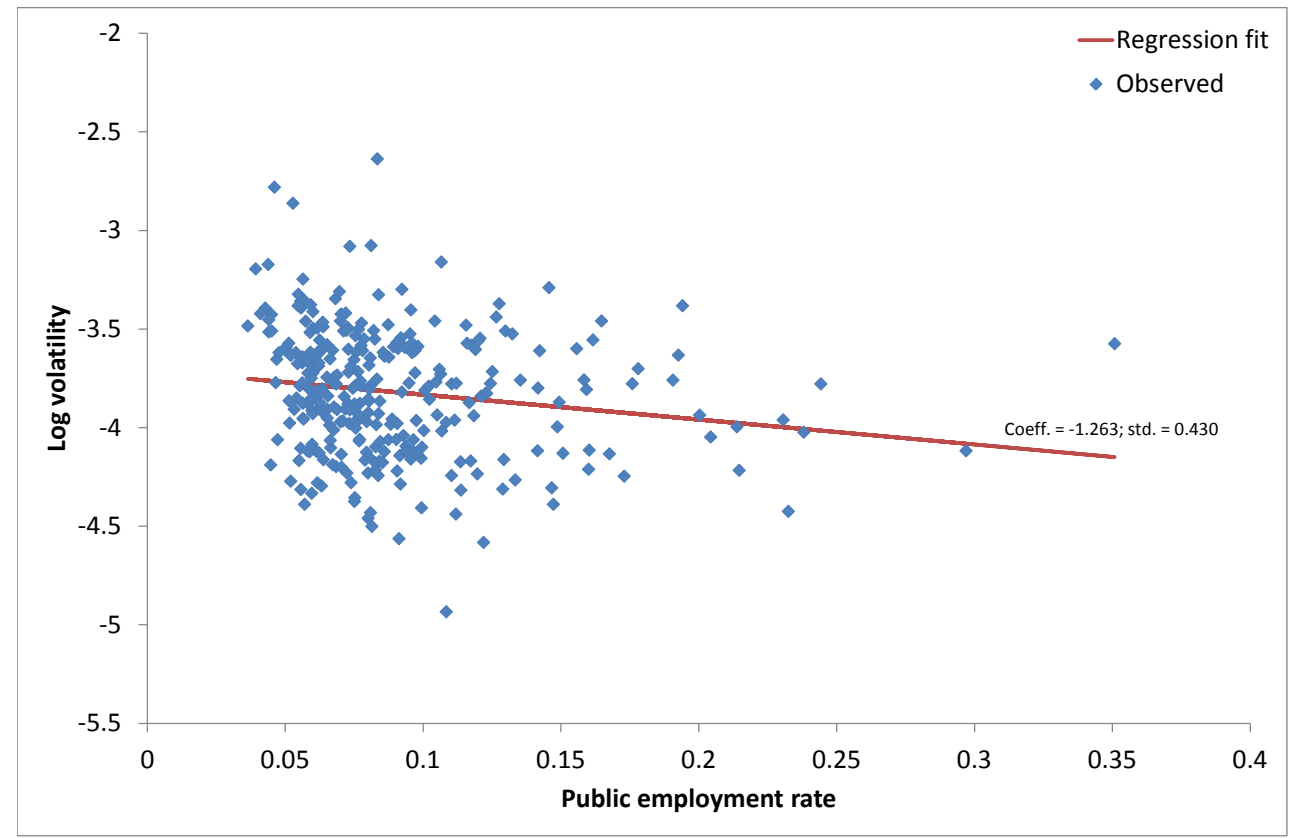

This figure shows the average public employment rate (as a share of population) and log volatility (the log standard deviation of private employment growth) for the metro areas in our full sample. The red line gives the best fit based on an OLS regression. Sample: 2001-2013. Source: BEA and authors' calculations. 
Figure 2: Log public wage premium vs. log volatility

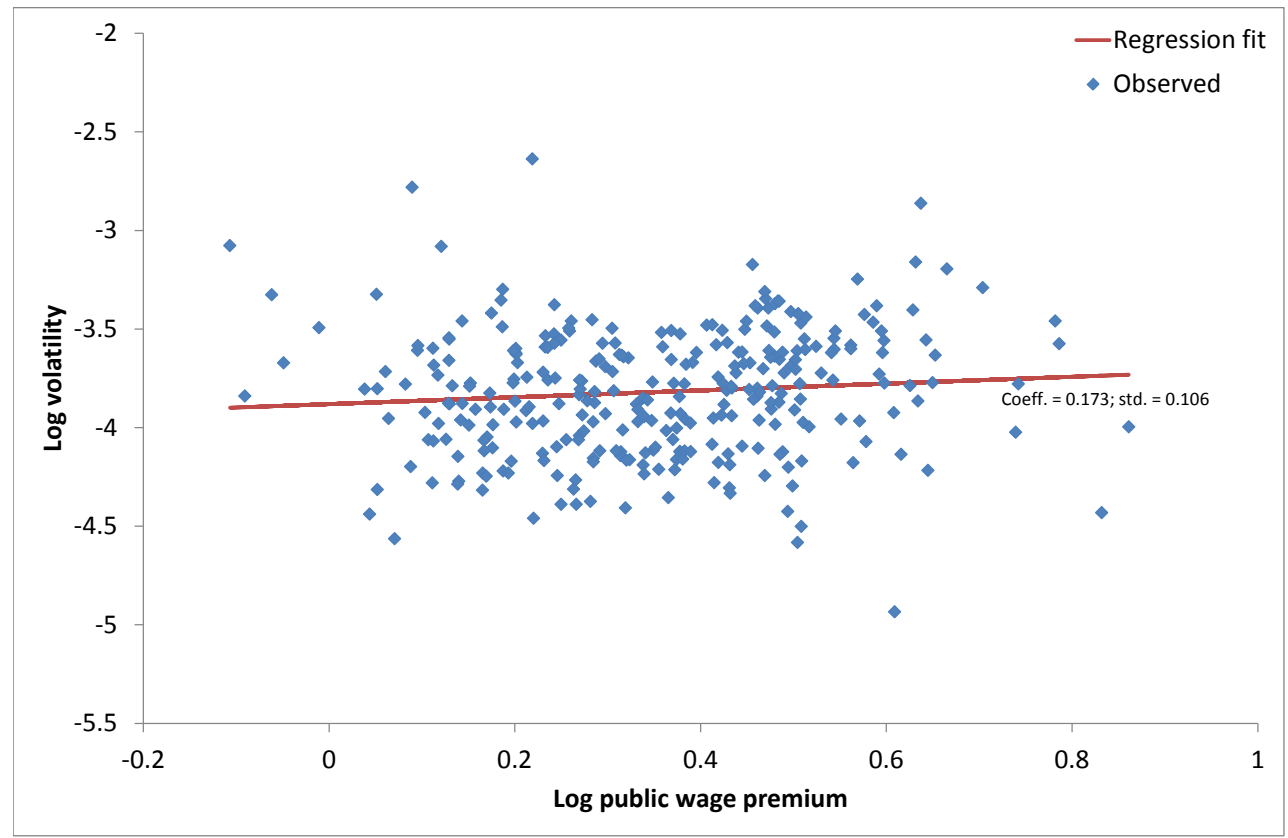

This figure shows the average log public wage premium (relative to private wages) and log volatility (the log standard deviation of private employment growth) for the metro areas in our full sample. The red line gives the best fit based on an OLS regression. Sample: 2001-2013. Source: BEA and authors' calculations. 